\title{
Supplier Selection Analysis Using Minmax Multi Choice Goal Programming Model
}

\author{
Novi Rustiana Dewi' ${ }^{1}$ Eka Susanti2 , Bambang Suprihatin ${ }^{3}$, Endro Setyo Cahyono ${ }^{4}$, \\ Anggun Permata ${ }^{5}$, Nurul Fadhila Yanita ${ }^{6}$
}

1,2,3,4,5,6 Department of Mathematics, Universitas Sriwijaya

Email: novirustiana@unsri.ac.id, eka_susanti@mipa.unsri.ac.id, endrosetyo_c@yahoo.co.id, bambangs@unsri.ac.id

\begin{abstract}
Production control, inventory and distribution is an important factor in trading activities. These three factors are discussed in a system called Supply Chain Management (SCM). Procurement of goods from a company or trading business related to suppliers. In some cases, there are several suppliers that can be assessed by considering certain factors. In certain cases, the data from several factors that are considered are uncertainty, so the fuzzy approach can be used. The MINMAX Multi Choice Goal Programming model can be used to solve fuzzy supplier selection problems with linear membership function. It can be applied to selecting supplier of Brastagi Oranges. There are four suppliers, namely Jaya, Mako, Baros. Gina. There are three factor to consider, cost, quality and delivery. The decision maker selects the best supplier for ordering $17000 \mathrm{~kg}$ Brastagi oranges. The results, the best supplier is Gina with an order quantity of 10000 $\mathrm{kg}$ and Mako with a total order of $7000 \mathrm{~kg}$.
\end{abstract}

Keywords: fuzzy; MINMAX multi choice goal programming; supply chain management; supplier selection

\section{INTRODUCTION}

Supply chain management has three main components, namely the process of obtaining suppliers of raw materials, the process of changing raw materials into finished products and the product distribution process. The first stage in the supply chain is supplier selection. Selection of suppliers aims to get products with good quality and competitive prices. Supplier selection is related to the process of procuring goods to meet customer demands. price and quality, time of delivery is a consideration in supplier's selection, especially for perishable products. Fruit is a type of product that does not last long if not stored in the refrigerator.

Research related to supply chains with application in various fields and solutions have been carried out with several approaches. The application of fuzzy TOPSIS in supplier selection was introduced by [1]. The fuzzy approach is also used by [2] in the selection of suppliers in manufacturing companies. The application of the supply chain concept to inventory control and supplier selection for planning new product production in several planning horizons was carried out by [3]. Discussion of supply chain problems 
by considering price, supply and demand factors is carried out by [4] and an efficient Lagrangian relaxation algorithm is proposed to solve the model. A discussion of bioethanol supply chain network problems with a robust approach was introduced [5]. A deterministic approach to solving the supply chain problem of food product distribution is discussed by [6]. The application of the mix integer programming model to the distribution and supply chain problems of liquid helium is given by [7]. The research of the [8] is combines the concepts of siting, inventory and routing in the supply chain.

There are two main studies related to the supplier selection model to be used, namely the concept of fuzzy and fuzzy goal programming. The Goal Programming (GP) model is used in problems with several objectives to be achieved simultaneously. The GP model with fuzzy numbers is called the Fuzzy Goal Programming (FGP) model. The concept of FGP with random variables was introduced by [9]. Fuzzy and probabilistic approaches to the FGP model are discussed by [10]. Completion of the FGP model with a genetic algorithm is discussed by [11]. Research [12] uses a multi-choice goal programming model to determine energy renewal facilities. [13] used the FGP model in production planning. The choice of waste transportation mode using the FGP model was introduced by [14]. The application of the Weighted Goal Programming model in the urban planning process is given by [15]. The application of the GP model in capital management is given by [16]. The use of the FGP model in transportation problems with several modes of transportation is given by [17].

The research that has been mentioned is the implementation of the supply chain concept to supplier, inventory and distribution components. This research will discuss the problem of selecting suppliers of Brastagi oranges using MINMAX Multi Choice Goal Programming models (Minmax MCGP). The research focus is on component suppliers. This research is a basic research by developing the MINMAX Multi Choice Goal Programming introduced by [2]. In [2], the fuzzy number used is the trapezoid fuzzy number by considering the factors of price, quality and technology offered. In this study, price, quality and time of delivery are considering. Linear membership function is used to define these tree factor.

\section{METHODS}

The steps for completing the supplier selection using the MINMAX MCGP method are:

1. Data Collection and Description

The data used in this study is primary, consist of data on the purchase with the parameters of cost, quality and delivery. The data collection period is from 18 February to 18 March 2020.

2. Determine the fuzzy triangular membership value for the goal of price, quality and delivery. Following are given fuzzy membership functions for the respective three goals, in order of price, quality and timeliness of delivery which are formulated based on the data in step 1 . The restriction value of variable $c, k, d$ is determined based on the data in step 1.

$$
\mu(c)=\left\{\begin{array}{cl}
1, & c \leq 7800 \\
1-\left[\frac{\left(c-S L_{1}(c)\right)}{S L_{2}(c)-S L_{1}(c)}\right], & 7800 \leq c \leq 10000 \\
0, & c \geq 10000
\end{array}\right.
$$




$$
\begin{gathered}
\mu(k)=\left\{\begin{array}{cc}
1, & k \geq 100 . \\
\frac{k}{S L_{2}(k)}, & 0<k \leq 100 . \\
0, & k \leq 0 .
\end{array}\right. \\
\mu(d)=\left\{\begin{array}{rc}
1, & d \geq 100 . \\
\frac{d}{S L_{2}(d)}, & 0<d \leq 100 . \\
0, & d \leq 0 .
\end{array}\right.
\end{gathered}
$$

Where

$\mu(c)$ is the membership function for the cost.

$\mu(k)$ is the membership function for the quality.

$\mu(d)$ is membership function for delivery

$k$ is the percentage of average supplier quality.

$S L_{1}(c)$ is Satisfaction Level lower bound for the unit cost.

$S L_{2}(c)$ is Satisfaction Level upper bound for the unit cost.

$S L_{2}(k)$ is Satisfaction Level upper bound for the unit quality.

$S L_{2}(d)$ is Satisfaction Level upper bound for the unit delivery.

3. The MINMAX MCGP model formulation based on the membership function values defined in Step 2. The following is the MINMAX MCGP model introduced by [2].

Min $D$

\section{Subject to}

$$
\begin{aligned}
& D \geq \alpha_{i} d_{i}^{+}+\beta_{i} d_{i}^{-}, i=1,2, \ldots m, \\
& D \geq \delta_{i}\left(e_{i}^{+}+e_{i}^{-}\right), i=1,2, \ldots m, \\
& \mu\left(x_{i}\right)-d_{i}^{+}+d_{i}^{-}=y_{i}, \quad i=1,2, \ldots m, \\
& y_{i}-e_{i}^{+}+e_{i}^{-}=g_{i, \max }, \quad i=1,2, \ldots, m, \\
& g_{i, \min } \leq y_{i} \leq g_{i, \max }, i=1,2, \ldots, m, \\
& d_{i}^{+}, d_{i}^{-}, e_{i}^{+}, e_{i}^{-} \geq 0, i=1,2, \ldots, m,
\end{aligned}
$$

where

$$
\begin{array}{ll}
D & : \text { the deviation variable of the objective function } \\
\alpha_{i} \text { and } \beta_{i} & : \text { weight of the positive deviation penalty in the objective function } \\
d_{i}^{+} \text {and } d_{i}^{-} & : \text {positive and negative deviation of the objective function } \\
\delta_{i} & : \text { the sum of the deviation in the objective function } \\
e_{i}^{+} \text {and } e_{i}^{-} & : \text {positive and negative deviation on }\left|y_{i}-g_{i, \max }\right| . \\
y_{i} & : \text { continuous variable with a range of interval value } \\
g_{i, \min } \text { and } g_{i, \max }: \text { minimum and maximum } y_{i} \text { value } \\
\mu\left(x_{i}\right) \quad: \text { membership function for the supplier to } i
\end{array}
$$

4. Completion of the model obtained in step (4) uses Lingo 13.0 software

5. Analyses and conclusion 


\section{RESULTS AND DISCUSSION}

This research discusses supplier selection problem of citrus fruits for the type of Brastagi oranges. The data used are primary data with a data collection period of 30 ordering periods. The research was conducted at a fruit shop in Palembang. The following is given the research data.

Table 1. Ordering the Data for Each Supplier

\begin{tabular}{|c|c|c|c|c|c|c|c|c|c|c|}
\hline \multirow{2}{*}{ No } & \multirow{2}{*}{$\begin{array}{l}\text { Supplie } \\
\text { r Name }\end{array}$} & \multicolumn{2}{|c|}{ Ordering } & \multicolumn{2}{|c|}{ delivery } & \multicolumn{2}{|c|}{$\begin{array}{c}\text { On } \\
\text { time } \\
\text { deliv } \\
\text { ery }\end{array}$} & \multicolumn{2}{|c|}{ Price offered } & \multirow{2}{*}{$\begin{array}{c}\text { Prece } \\
\text { ntage } \\
\text { of } \\
\text { quali } \\
\text { y (\%) }\end{array}$} \\
\hline & & Date & Month & Date & Month & & & $\begin{array}{c}\text { Cost } \\
(@ k g)\end{array}$ & Total & \\
\hline 1 & Jaya & 21 & Feb & 21 & Feb & $\sqrt{ }$ & - & 8500 & 45900000 & 80 \\
\hline 2 & Mako & 21 & Feb & 21 & Feb & $\sqrt{ }$ & - & 8000 & 43200000 & 85 \\
\hline 3 & Baros & 22 & Feb & 24 & Feb & - & $\sqrt{ }$ & 8500 & 45900000 & 80 \\
\hline 4 & Gina & 22 & Feb & 22 & Feb & $\sqrt{ }$ & - & 9000 & 48600000 & 95 \\
\hline 5 & Jaya & 23 & Feb & 23 & Feb & $\sqrt{ }$ & - & 8500 & 45900000 & 85 \\
\hline 6 & Mako & 24 & Feb & 24 & Feb & $\sqrt{ }$ & - & 8500 & 45900000 & 90 \\
\hline 7 & Baros & 25 & Feb & 25 & Feb & $\sqrt{ }$ & - & 8000 & 43200000 & 80 \\
\hline 8 & Mako & 25 & Feb & 25 & Feb & $\sqrt{ }$ & - & 9000 & 48600000 & 90 \\
\hline 9 & Gina & 26 & Feb & 26 & Feb & $\sqrt{ }$ & - & 9000 & 48600000 & 90 \\
\hline 10 & Mako & 27 & Feb & 28 & Feb & - & $\sqrt{ }$ & 8000 & 43200000 & 85 \\
\hline 11 & Jaya & 27 & Feb & 27 & Feb & $\sqrt{ }$ & - & 8500 & 45900000 & 85 \\
\hline 12 & Baros & 28 & Feb & 28 & Feb & $\sqrt{ }$ & - & 8000 & 43200000 & 85 \\
\hline 13 & Mako & 29 & Feb & 1 & Maret & - & $\sqrt{ }$ & 9000 & 48600000 & 85 \\
\hline 14 & Gina & 29 & Feb & 29 & Feb & $\sqrt{ }$ & - & 9500 & 51300000 & 90 \\
\hline 15 & Jaya & 1 & Maret & 2 & Maret & - & $\sqrt{ }$ & 8500 & 45900000 & 85 \\
\hline 16 & Mako & 1 & Maret & 1 & Maret & $\sqrt{ }$ & - & 9000 & 48600000 & 95 \\
\hline 17 & Baros & 2 & Maret & 2 & Maret & $\sqrt{ }$ & - & 9000 & 48600000 & 80 \\
\hline 18 & Mako & 3 & Maret & 3 & Maret & $\sqrt{ }$ & - & 9000 & 48600000 & 85 \\
\hline 19 & Gina & 4 & Maret & 4 & Maret & $\sqrt{ }$ & - & 9500 & 51300000 & 85 \\
\hline 20 & Jaya & 5 & Maret & 6 & Maret & - & $\sqrt{ }$ & 9000 & 48600000 & 85 \\
\hline 21 & Baros & 5 & Maret & 5 & Maret & $\sqrt{ }$ & - & 9000 & 48600000 & 80 \\
\hline 22 & Mako & 6 & Maret & 6 & Maret & $\sqrt{ }$ & - & 9000 & 48600000 & 90 \\
\hline 23 & Gina & 7 & Maret & 7 & Maret & $\sqrt{ }$ & - & 9500 & 51300000 & 95 \\
\hline 24 & Jaya & 8 & Maret & 10 & Maret & - & $\sqrt{ }$ & 9000 & 48600000 & 80 \\
\hline 25 & Baros & 8 & Maret & 8 & Maret & $\sqrt{ }$ & - & 9000 & 48600000 & 85 \\
\hline 26 & Gina & 9 & Maret & 9 & Maret & $\sqrt{ }$ & - & 9500 & 51300000 & 95 \\
\hline 27 & Mako & 9 & Maret & 9 & Maret & $\sqrt{ }$ & - & 9000 & 48600000 & 90 \\
\hline 28 & Jaya & 10 & Maret & 12 & Maret & - & $\sqrt{ }$ & 8500 & 45900000 & 85 \\
\hline 29 & Baros & 10 & Maret & 10 & Maret & $\sqrt{ }$ & - & 9000 & 48600000 & 80 \\
\hline 30 & Gina & 11 & Maret & 11 & Maret & $\sqrt{ }$ & - & 9500 & 51300000 & 85 \\
\hline 31 & Jaya & 12 & Maret & 13 & Maret & - & $\sqrt{ }$ & 9000 & 48600000 & 80 \\
\hline 32 & Mako & 13 & Maret & 13 & Maret & $\sqrt{ }$ & - & 9000 & 48600000 & 85 \\
\hline 33 & Jaya & 13 & Maret & 14 & Maret & - & $\sqrt{ }$ & 9000 & 48600000 & 90 \\
\hline
\end{tabular}




\begin{tabular}{ccccccccccc}
34 & Gina & 14 & Maret & 14 & Maret & $\sqrt{ }$ & - & 9500 & 51300000 & 90 \\
35 & Baros & 15 & Maret & 16 & Maret & - & $\sqrt{ }$ & 8500 & 45900000 & 85 \\
36 & Mako & 15 & Maret & 15 & Maret & $\sqrt{ }$ & - & 9000 & 48600000 & 90 \\
37 & Gina & 16 & Maret & 16 & Maret & $\sqrt{ }$ & - & 9500 & 51300000 & 90 \\
38 & Jaya & 16 & Maret & 18 & Maret & - & $\sqrt{ }$ & 8500 & 45900000 & 85 \\
39 & Mako & 17 & Maret & 17 & Maret & $\sqrt{ }$ & - & 9000 & 48600000 & 90 \\
40 & Gina & 19 & Maret & 18 & Maret & - & $\sqrt{ }$ & 9000 & 48600000 & 95 \\
41 & Baros & 19 & Maret & 19 & Maret & $\sqrt{ }$ & - & 8500 & 45900000 & 90 \\
42 & Jaya & 19 & Maret & 20 & Maret & - & $\sqrt{ }$ & 8500 & 45900000 & 80 \\
43 & Mako & 19 & Maret & 21 & Maret & - & $\sqrt{ }$ & 8500 & 45900000 & 80 \\
44 & Gina & 20 & Maret & 20 & Maret & $\sqrt{ }$ & - & 9000 & 48600000 & 90 \\
45 & Jaya & 20 & Maret & 22 & Maret & - & $\sqrt{ }$ & 8000 & 43200000 & 80 \\
46 & Baros & 21 & Maret & 21 & Maret & $\sqrt{ }$ & - & 8500 & 45900000 & 90 \\
47 & Mako & 21 & Maret & 22 & Maret & - & $\sqrt{ }$ & 8500 & 45900000 & 85 \\
\hline
\end{tabular}

(Source : PD Wibowo, 21 februari until Maret 2020)

Table 1 can determine the percentage of on-time delivery, the variable price offered, and the varying percentage of quality citrus in good condition with the total of all oranges sent by the supplier. The price value of each supplier is obtained by adding up each price in purchases divided by the number of investments, determined the average value for each data cost, quality, and timeliness. The calculation results are given in Table 2 below.

Table 2. Value Percentage Criteria from Four Suppliers

\begin{tabular}{cccccc}
\hline Supplier & $\boldsymbol{x}_{\boldsymbol{i}}$ & Cost (Rp) & Quality (\%) & Delivery (\%) & $\begin{array}{c}\text { Total Order } \\
\text { (kg) }\end{array}$ \\
\hline Jaya & $\boldsymbol{x}_{\mathbf{1}}$ & 8625 & 83,33 & 25,00 & 64800 \\
Mako & $\boldsymbol{x}_{\mathbf{2}}$ & 8750 & 87,50 & 71,43 & 75600 \\
Baros & $\boldsymbol{x}_{\mathbf{3}}$ & 8600 & 83,50 & 80,00 & 54000 \\
Gina & $\boldsymbol{x}_{\mathbf{4}}$ & 9318 & 90,91 & 90,91 & 59400 \\
\hline
\end{tabular}

Determined the degree of membership for the level of satisfaction of the Decision Maker (DM) of each goal using (1), (2), (3). The calculation results are given in Table 3 below:

Table 3. Degree of Membership for DM Satisfaction Level of Each Goal

\begin{tabular}{cccccc}
\hline Decision & Lowest & & & Highest \\
\hline $\boldsymbol{c}$ : Cost & $>10000$ & 8465.4 & 8243.6 & 8021.8 & 7800 \\
SL $(c)$, Satisfaction Level c & 0 & 0,7 & 0,8 & 0,9 & 1 \\
$\boldsymbol{k}:$ Kualitas & 0 & 40 & 60 & 80 & 100 \\
SL $(k)$, Satisfaction Level $k$ & 0 & 0,4 & 0,6 & 0,8 & 1 \\
$\boldsymbol{d}:$ Ketepatan Waktu & 0 & 40 & 60 & 80 & 100 \\
$\mathrm{SL}(d)$, Satisfaction Level $\boldsymbol{d}$ & 0 & 0,4 & 0,6 & 0,8 & 1 \\
\hline
\end{tabular}

The value of the level of satisfaction is in the interval $[0,1]$. Based on Table 3, it is known that for the lowest decision value, DM gives a satisfaction level value of 0 . For the highest decision value, DM gives a satisfaction level value 1 . The level of satisfaction for each goal of cost, quality, and time delivery is determined based on equations (1), (2), and (3). The results are given in Table 4 below. 
Table 4. Membership Function Value for Each Goal

\begin{tabular}{|c|c|c|c|c|}
\hline Supplier & $\begin{array}{l}\text { Amount of } \\
\text { Order }\end{array}$ & Cost & Quality & Delivery \\
\hline Jaya & $x_{1}$ & 0,625 & 0,83 & 0,25 \\
\hline Mako & $x_{2}$ & 0,568 & 0,88 & 0,71 \\
\hline Baros & $x_{3}$ & 0,636 & 0,84 & 0,8 \\
\hline Gina & $x_{4}$ & 0,31 & 0,91 & 0,91 \\
\hline \multicolumn{2}{|c|}{ Average } & 0,53 & 0,865 & 0,6675 \\
\hline \multicolumn{2}{|c|}{ Maximum Value } & 0,636 & 0,91 & 0,91 \\
\hline
\end{tabular}

The lower bound for the price goal is determined based on the average price value multiplied by the minimum order. The upper price is the product of the maximum value of the price times the maximum order. The same calculation is done for quality goals and on time delivery. We obtained a lower bound and an upper bound for the goal value of price, quality and on time delivery respectively 28876,5; 48081,6; 49013,2; 70308; 36045; 68796. The formulation of the MINMAX MCGP model (4) the problem of supplier's selection of Brastagi Oranges with a maximum order quantity for each supplier of $10000 \mathrm{~kg}$, minimum order of $15000 \mathrm{~kg}$ and a maximum of $17000 \mathrm{~kg}$ is given as follows.

Minimum D

Subject to

$$
\begin{aligned}
& D \geq 3 d_{1}^{+}+d_{1}^{-} \\
& D \geq e_{1}^{+}+e_{1}^{-} ; D \geq d_{2}^{+}+5 d_{2}^{-} \\
& D \geq e_{2}^{+}+e_{2}^{-} ; D \geq d_{3}^{+}+3 d_{3}^{-} ; D \geq e_{3}^{+}+e_{3}^{-} \\
& 0,625 x_{1}+0,568 x_{2}+0,636 x_{3}+0,31 x_{4}-d_{1}^{+}+d_{1}^{-}=y_{1} \\
& y_{1}-e_{1}^{+}+e_{1}^{-}=48081,6 \\
& 28876,5 \leq y_{1} \leq 48081,6 \\
& 0,83 x_{1}+0,88 x_{2}+0,84 x_{3}+0,91 x_{4}-d_{2}^{+}+d_{2}^{-}=y_{2} \\
& y_{2}-e_{2}^{+}+e_{2}^{-}=70308 \\
& 49013,2 \leq y_{2} \leq 70308 \\
& 0,25 x_{1}+0,71 x_{2}+0,8 x_{3}+0,91 x_{4}-d_{3}^{+}+d_{3}^{-}=y_{3} \\
& y_{3}-e_{3}^{+}+e_{3}^{-}=68796 \\
& 36045 \leq y_{3} \leq 68796 \\
& x_{1} \leq 10000 ; x_{2} \leq 10000 ; x_{3} \leq 10000 ; x_{4} \leq 10000 \\
& x_{1}+x_{2}+x_{3}+x_{4} \geq 15000 ; x_{1}+x_{2}+x_{3}+x_{4} \leq 17000 \\
& d_{1}^{+}, d_{1}^{-}, e_{1}^{+}, e_{1}^{-}, y_{1}, y_{2}, y_{3} \geq 0
\end{aligned}
$$

Solving the linear model (5) uses LINGO 13 software and the solution is obtained in Table 5 below. 
Table 5. MINMAX MCGP Model Solution for Citrus Fruit Supplier Selection

\begin{tabular}{ccc}
\hline No & Variable & Value \\
\hline 1. & $x_{1}$ & 0 \\
2. & $x_{2}$ & 7000 \\
3. & $x_{3}$ & 0 \\
4. & $x_{4}$ & 10000 \\
5. & $y_{1}$ & 39463.88 \\
6. & $y_{2}$ & 28876.50 \\
7. & $y_{3}$ & 36764.17 \\
8. & $D_{1}^{+}$ & 0 \\
9. & $D_{1}^{-}$ & 32387.88 \\
10. & $e_{1}^{+}$ & 0 \\
11. & $e_{1}^{-}$ & 8617.725 \\
12. & $D_{2}^{+}$ & 0 \\
13. & $D_{2}^{-}$ & 13616.5 \\
14. & $e_{2}^{+}$ & 0 \\
15. & $e_{2}^{-}$ & 39919.50 \\
16. & $D_{3}^{+}$ & 0 \\
17. & $D_{3}^{-}$ & 22694.17 \\
18. & $e_{3}^{+}$ & 0 \\
19. & $e_{3}^{-}$ & 32031.83 \\
20. & $D$ & 68082.50 \\
\hline
\end{tabular}

In Table 5, for a maximum total order of $17000 \mathrm{~kg}$, an order is recommended for $x_{2}$ (Supplier Mako) and $x_{4}$ (Supplier Gina). The values of $y_{1}$ (Aspiration Rate G1) $=39463.88$, $y_{2}$ (Aspiration Rate G2) $=28876.50, y_{3}$ (Aspiration Rate G3) $=36764.17$, and other deviations are given in Table 5. The values of $x_{1}, x_{2}, x_{3}$, and $x_{4}$ are $0,7000,0,10000$, respectively. It can be concluded that the order for selecting the best supplier is Supplier Gina with an order quantity of $10000 \mathrm{~kg}$, Supplier Mako with an order quantity of 7000 $\mathrm{kg}$.

\section{CONCLUSIONS}

the results obtained the best supplier for orders of a maximum of $17000 \mathrm{~kg}$ are Gina Supplier with a total order of $1000 \mathrm{~kg}$ of Brastagi oranges and Mako supplier with a maximum order of $7000 \mathrm{~kg}$. The best supplier order is obtained by looking at the difference in the value of the deviation from the target for each goal of price, quality and delivery. The difference in goal value results in a different order of supplier selection.

\section{ACKNOWLEDGMENTS}

This Research is supported by Universitas Sriwijaya through Sains Teknologi dan Seni (SATEKS) Research Scheme with the number of the research assignment contract number 0163.177/UN9/SB3.LPPM.PT/2020.

\section{REFERENCES}

[1] R. Kiani, M. Goh, and N. Kiani, "Supplier Selection with Shannon Entropy and Fuzzy TOPSIS in the Context of Supply Chain Risk Management," Procedia - Soc. Behav. Sci., vol. 235, no. October, pp. 216-225, 2016.

[2] H. Ho, "The Supplier Selection Problem of a Manufacturing Company using the Weighted Multi-Choice Goal Programming and MINMAX Multi-Choice Goal 
Programming," Appl. Math. Model., vol. 75, pp. 819-836, 2019.

[3] A. Negahban and M. Dehghanimohammadabadi, "Optimizing the Supply Chain Configuration and Production-Sales Policies for New Products over Multiple Planning Horizons," Int. J. Prod. Econ., vol. 196, pp. 150-162, 2018.

[4] A. Ahmadi-javid and P. Hoseinpour, "A location-Inventory-Pricing Model in a Supply Chain Distribution Network with Price-Sensitive Demands and Inventory-Capacity Constraints," Transp. Res. PART E, vol. 82, pp. 238-255, 2015.

[5] H. Ghaderi, A. Moini, and M. S. Pishvaee, "A Multi-Objective Robust Possibilistic Programming Approach to Sustainable Switchgrass-Based Bioethanol Supply Chain Network Design," J. Clean. Prod., vol. 179, pp. 368-406, 2018.

[6] J. H. M. Manders, M. C. J. Caniëls, and P. W. Th, "Exploring supply chain fl exibility in a FMCG food supply chain,” J. Purch. Supply Manag., vol. 22, no. 3, pp. 181-195, 2016.

[7] E. Malinowski, M. H. Karwan, J. M. Pinto, and L. Sun, "A mixed-integer programming strategy for liquid helium global supply chain planning," Transp. Res. Part E, vol. 110, no. July 2017, pp. 168-188, 2018.

[8] X. Zheng, M. Yin, and Y. Zhang, "Integrated Optimization of Location, Inventory and Routing In Supply Chain Network Design," Transp. Res. Part B, vol. 121, pp. 1-20, 2019.

[9] Z. Qin, "Uncertain Random Goal Programming," Fuzzy Optim. Decis. Mak., vol. 17, no. 4, pp. 375-386, 2018.

[10] S. . Barik, "Probabilistic Fuzzy Goal Programming Problem Involving Pareto Distribution : Some Additive Approaches," Fuzzy Inf. Eng., vol. 7, pp. 227-244, 2015.

[11] P. Biswas, "Fuzzy Goal Programming Approach to Solve Linear Multilevel Programming Problems using Genetic Algorithm," Int. J. Comput. Appl., vol. 115, no. 3, pp. 10-19, 2015.

[12] C. Chang, "Multi-choice goal programming model for the optimal location of renewable energy facilities," Renew. Sustain. Energy Rev., vol. 41, pp. 379-389, 2015.

[13] L. Chen, W. Ko, and F. Yeh, "Approach Based on Fuzzy Goal Programming and Quality Function Deployment For New product Planning," Eur. J. Oper. Res., vol. 259, no. 2, pp. 654-663, 2016.

[14] E. Susanti, O. Dwipurwani, and E. Yuliza, "Optimasi Kendaraan Pengangkut Sampah Menggunakan Model Fuzzy Goal Programming,” J. Mat., vol. 7, no. 2, pp. 119-123, 2017.

[15] R. Jayaraman, C. Colapinto, D. La, and T. Malik, "A Weighted Goal Programming model for planning sustainable development applied to Gulf Cooperation Council Countries," Appl. Energy, vol. 185, no. 2, 1 January 2017, pp. 1931-1939, 2016.

[16] M. Dash and R. Hanuman, "A Goal Programming Model for Working Capital," J. Manag. Sci., vol. 5, no. 1, pp. 7-16, 2015.

[17] L. Chen, J. Peng, and B. Zhang, "Uncertain Goal Programming Models for Bicriteria Solid Transportation Problem," Appl. Soft Comput. J., 2016. 